\title{
Notes on the vocalizations of Stolid Flycatcher (Myiarchus stolidus) and La Sagra's Flycatcher (Myiarchus sagrae)
}

Peter Boesman

In the following we briefly analyze and compare voice of Stolid Flycatcher (Myiarchus stolidus) and La Sagra's Flycatcher (Myiarchus sagrae). We also try to quantify the extent of any vocal differences using the criteria proposed by Tobias et al. (2010), as a support for taxonomic review. We have made use of sound recordings available on-line from Xeno Canto (XC) and Macaulay Library (ML).

Both species have a dawn song, a commonly-heard day-time call and several interaction or excitement calls (Fig. 1). Vocabulary of both species is thus quite extensive.

We have therefore made a quick inventory and analysis of the entire vocabulary.

\section{M. sagrae}

1. dawn song (4 recordings)

\section{length}

$0.69-0.98 \mathrm{~s}$

length 1st note

$0.09-0.14 \mathrm{~s}$

\# of notes

4-6

$\min$. freq.

$2350-2600 \mathrm{~Hz}$

max. freq.

$4400-5200 \mathrm{~Hz}$

freq. range

$1850-2800 \mathrm{~Hz}$

\section{2. a short upslurred "whit!" call (15 recordings)}

This seems to be the primary day-time call Length $\quad 0.075-0.15 \mathrm{~s}$

min. freq. $\quad 2200-2600 \mathrm{~Hz}$

max. freq. $\quad 4800-5180 \mathrm{~Hz}$

freq. range $\quad 2200-2800 \mathrm{~Hz}$

3. a burry "krrri" (3 recordings)

\begin{tabular}{ll}
\hline length & $0.21-0.28 \mathrm{~s}$ \\
min. freq. & $2600-3500 \mathrm{~Hz}$ \\
max. freq. & $4600-5300 \mathrm{~Hz}$
\end{tabular}

4. a subdued "wi-ri-ri-ri" (2 recordings)

\begin{tabular}{ll}
\hline length & $0.24-0.40 \mathrm{~s}$ \\
min. freq. & $1900-2400 \mathrm{hz}$ \\
max. freq. & $4600-4660 \mathrm{~Hz}$ \\
$\#$ notes & $4-5$
\end{tabular}

and other vocalizations only found once. 


\section{HANDBOOK OF THE \\ BIRDS PF/THE WORLD}

M. stolidus

1. dawn song (4 recordings)

length

length 1st note

\# of notes

min. freq.

max. freq.

freq. range

\section{ORNITHOLOGICAL NOTES}

$0.99-1.16 \mathrm{~s}$

$0.36-0.49 \mathrm{~s}$

3-5

$2170-2600 \mathrm{~Hz}$

$5000-5500 \mathrm{~Hz}$

$2500-3300 \mathrm{~Hz}$

\section{2. a long overslurred whistled "weew" (6 recordings)}

This seems to be the primary day-time call (possibly with the next one just a burry variant) Length $\quad 0.36-0.62 \mathrm{~s}$

min. freq. $\quad 2300-2800 \mathrm{~Hz}$

max. freq. $\quad 3340-4450 \mathrm{~Hz}$

freq. range $\quad 540-1900 \mathrm{~Hz}$

3. a long burry overslurred "wheerrr" (3 recordings)

length $\quad 0.37-0.53 \mathrm{~s}$

4. a buzzy "krrr" (3 recordings)

length $0.25-0.29 \mathrm{~s}$

similar to vocalization type 3 of sagrae, but base frequency much more pronounced

and other vocalizations only found once, such as a short "wi-di" and a harsh "chik!".

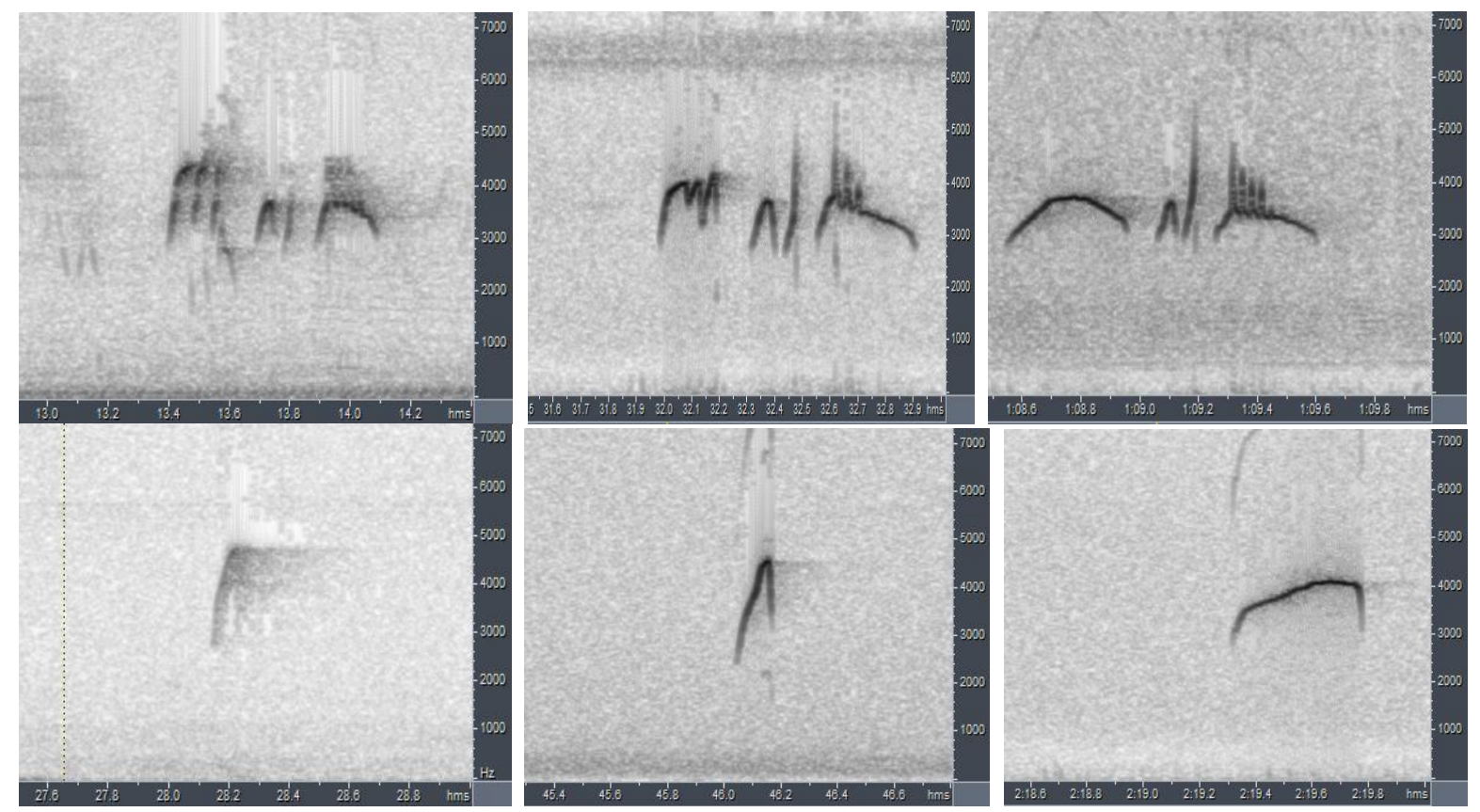

Figure 1: from top to bottom: dawn song of M.sagrae lucaysiensis (left), M.s. sagrae (middle) and M.stolidus dominicensis (right), commonest day-time call of $M$. sagrae (left and middle) and M. stolidus (right) 

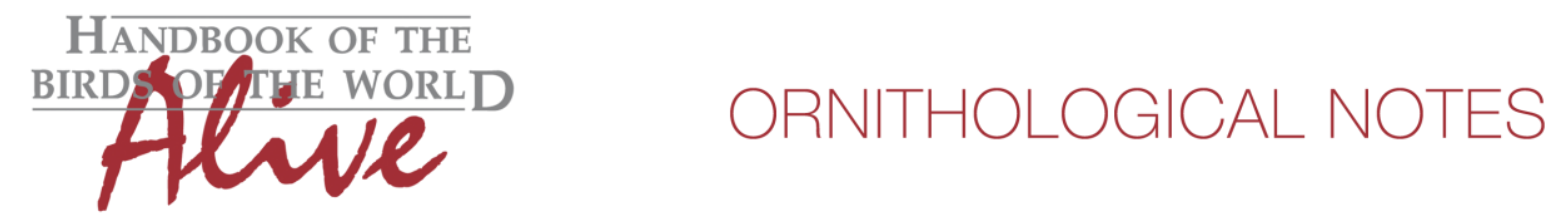

It is clear from this short analysis that the day-time vocabulary of both species is quite different.

If we compare the primary day-time call, than obviously difference in length (score 3) and frequency range (score 2-3) leads to a total score of 5- 6 by applying Tobias criteria.

Dawn song of both species shows similarities in that the two ending notes are very similar, but both songs can be told apart because $M$. stolidus always starts with a drawn-out whistle.

Differences here are length of first note (score 3 ) and total length of song phrase (score 2 ).

Primary day-time call is equally important (cfr. e.g. the Zimmerius cases), for which overall vocal score is about 5 .

Extensive play-back experiments have been carried out in the past (Lanyon 1667) to determine responses, and this was used to define species limits of the Myiarchus genus in the West-Indies. His work was probably the basis to re-elevate to species-rank $M$. stolidus and $M$. sagrae, different from prior arrangements by Hellmayr (1927) and Bond (1956).

This note was finalized on 14th July 2015 , using sound recordings available on-line at that moment. We would like to thank in particular the sound recordists who placed their recordings for this species on XC and ML: Michael Anderson, Lance Benner, Timothy Burr, Ian Davies, Paul Dean, Paul Driver, Jesse Fagan, Jon King, Wesley Lanyon, Linda Macaulay, Paul Marvin, Cedar Mathers-Winn, Eugene Morton, Ted Parker, Aidan Place and Mark Robbins.

\section{References}

Lanyon, W.E. (1967). Revision and probable evolution of the Myiarchus flycatchers of the West Indies. Bull. Amer. Mus. Nat. Hist. 136(6): 331-370.

Tobias, J.A., Seddon, N., Spottiswoode, C.N., Pilgrim, J.D., Fishpool, L.D.C. \& Collar, N.J. (2010). Quantitative criteria for species delimitation. Ibis 152(4): 724-746.

\section{Recommended citation}

Boesman, P. (2016). Notes on the vocalizations of Stolid Flycatcher (Myiarchus stolidus) and La Sagra's Flycatcher (Myiarchus sagrae). HBW Alive Ornithological Note 143. In: Handbook of the Birds of the World Alive. Lynx Edicions, Barcelona. (retrieved from

http://www.hbw.com/node/932068 on 16 August 2016). 